Article

\title{
Incidence of Trailer Frame Structure on Driver's Safety during Log Transportation
}

\author{
Marco Manzone * (D) and Angela Calvo \\ Department of Agricultural, Forest and Food Sciences, University of Torino, Largo Paolo Braccini, 2, \\ 10095 Grugliasco, Italy; angela.calvo@unito.it \\ * Correspondence: marco.manzone@unito.it; Tel.: +39-011-670-8638
}

Received: 29 September 2017; Accepted: 11 November 2017; Published: 18 November 2017

\begin{abstract}
The frame structure of the trailer may influence both the traction and the tractor-trailer stability, especially along sloped paths. The aim of this research was to analyze a trailer overturning and the strains on the connected tractors (wheeled, or crawled) during log transportation (loose or tied) along a hillside. Two two-axle trailers were used: tandem and turntable steering. Three types of measurements were carried out during the field tests: (i) the detachment from the ground of the rear upstream wheels (or crawler); (ii) the transversal and longitudinal strains occurring when the trailer overturned (and released the hooking system of the tractor); (iii) the lateral deviation of the rear wheels (or crawler) of the tractor. The study highlighted that the two-axle trailer with turntable steering combined with the crawl tractor gave better results in terms of safety during trailer overturning. In addition, independent of the type of trailer, a tied load was found to be more dangerous than a load restrained only by steel struts, because when overturning, the load forms a single unit with the trailer mass which increases the strains.
\end{abstract}

Keywords: frame structure; two-axle trailer; crawl tractor; wheel tractor; safety

\section{Introduction}

In the NACE (Nomenclature of the Economic Activities) statistics in Europe, the number of fatal accidents in agriculture and forestry lies in third place (14.8\%), after the activities of construction $(21.5 \%)$ followed by transportation and storage (16.7\%) [1]. Nevertheless, many accidents are not officially recorded [2].

Forestry and logging are among the most hazardous activities in agriculture: compared to other agricultural activities, the percentage of fatal accidents at work in this sector is never lower than $16 \%$ (Figure 1).

Tractors are among the highest causes of fatal accidents [1] and the most severe accidents are caused while the machine is operating in the field [3,4].

The main cause of deaths by tractors is machine overturning [5], especially when it is operating along sloped terrains for logging operations [6]. Machine overturning is due to the displacement of the center of gravity of the vehicle outside the stability baseline of the machine when it is moving forward. There are many reasons that affect the dynamic stability of the tractor $[7,8]$. They may depend on driver behavior (driving style, forward speed), on the environment (slope, rough terrain, stones, stems, potholes) or on the presence of additional weights connected to the tractor (trailers, towed implements, ballasts).

In a study conducted in 1991 it was demonstrated that the above factors were the cause of more than $50 \%$ of the tractor rollover accidents [9]. 


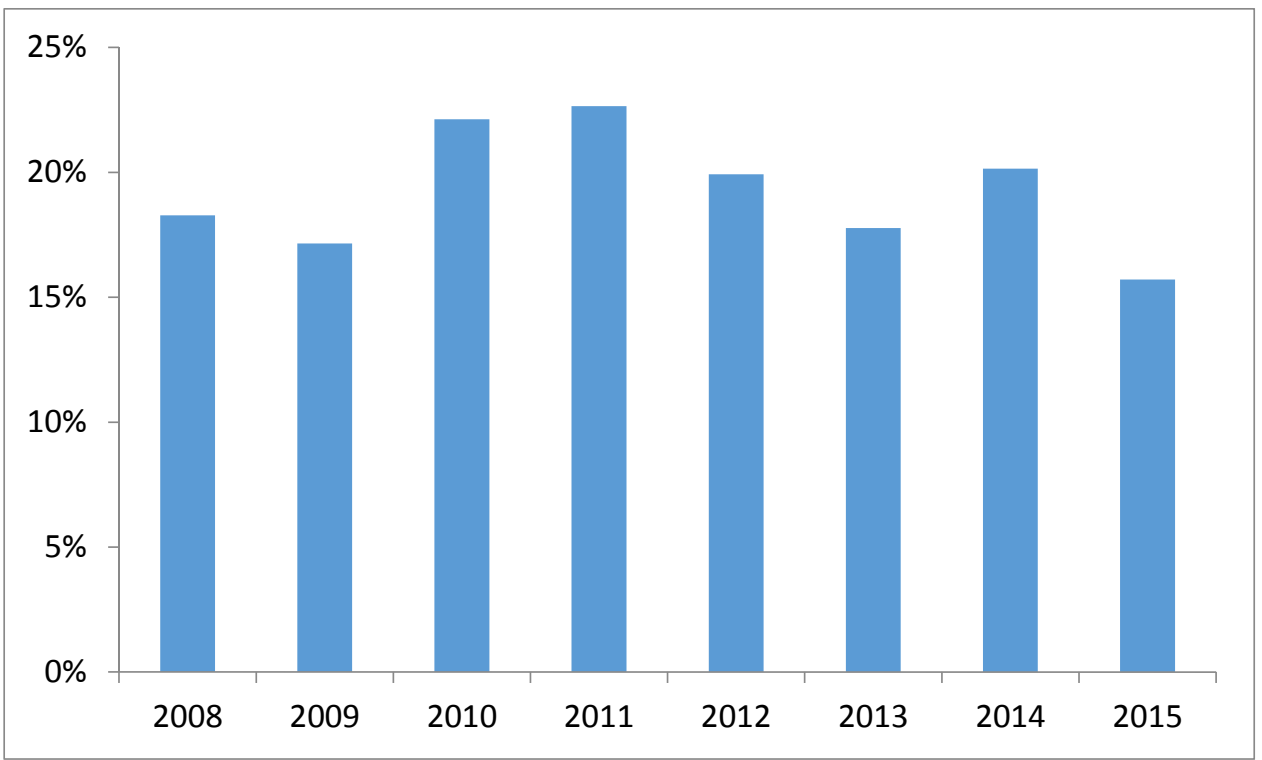

Figure 1. Fatal accidents during forestry and logging activities recorded in Europe, compared to other agricultural tasks (Source: Authors' elaboration of Eurostat data [1]).

Concerning trailers, the higher the center of gravity and the loading capacity, the higher is the risk of the convoy (tractor-trailer) overturning [10]. Studies on the stability of the tractor-trailer system have been carried out by several researchers [11-14]. Pereira et al. in 2011 [15] considered the critical conditions during the transportation of logs, while Lindroos and Wasterlund [16] analyzed the risks caused by the gross weight of a heavy trailer connected to a tractor with a low traction capacity. In the Italian alpine North-West regions (where sloped and rough terrains are spread) small old tractors and equipment are used [17], particularly in order to guarantee environmental resiliency and wood regeneration.

For many years in forestry and logging activities, trailers equipped with motor axles have been used, in order to improve the traction of the whole convoy. Moreover, the use of a crawler tractor, instead of a wheeled tractor, may well improve the convoy stability.

Also the frame structure of the trailer influences the traction and the stability, especially along sloped paths.

The aim of this research was to analyze trailer overturning and the strains on the connected tractor (one wheeled, one crawled) during log transportation (loose and tied) along a hillside, using two two-axles trailers with different characteristics: the first tandem, the second with turntable steering. The detachment from the ground of the rear upstream wheels and the side-slipping of the rear wheels (or crawler) of the two tractors as well as the transversal and longitudinal strains occurring when the trailer overturned were analyzed.

\section{Material and Methods}

\subsection{Tractors}

The technical characteristics of the two tractors used in the field tests (a 2WD and a crawler each with a mass of about $4200 \mathrm{~kg}$ ) are displayed in Table 1 . Both the tractors satisfied the minimum safety requirements required by the European Directive 2006/42 and they were equipped with roll over protection systems and seat belts. These tractors are very common for carrying out logging operations in the South of Europe. Moreover, two tractors with different characteristics were considered in evaluating the different behavior of the trailers during overturning. 
Table 1. Technical characteristics of the tractors.

\begin{tabular}{ccc}
\hline & NH T5.115 (A) & NH TK 4040M (B) \\
\hline Power (kW) & 84 & 65 \\
Mass (kg) & $4250 *$ & $4250 *$ \\
Propulsion system & wheels & tracks \\
Driving wheels & 4 & - \\
Rear wheel type & $540 / 65-34$ & - \\
Front wheel type & $440 / 65-24$ & - \\
Overall width (m) & 2.20 & 1.65 \\
\hline
\end{tabular}

Note: $\left({ }^{*}\right)$ The mass of the driver $(90 \mathrm{~kg})$ is not included in these values.

\subsection{Trailers}

A two-axle trailer in tandem and a two-axle trailer with turntable steering were used to perform the tests (Table 2).

Table 2. Technical characteristics of the used trailers.

\begin{tabular}{ccc}
\hline & Two-Axle in Tandem (1) & Two-Axle with Turntable Steering (2) \\
\hline Mass (kg) & 3150 & 3000 \\
Flatbed width (m) & 2.20 & 2.20 \\
Flatbed height (m) & 1.20 & 1.20 \\
Flatbed length (m) & 4.50 & 4.50 \\
Wheel dimension & $385 / 65 \mathrm{R} 195$ & $385 / 65 \mathrm{R} 195$ \\
Hooking height (m) & 0.55 & 1.10 \\
\hline
\end{tabular}

Note: $\left(^{*}\right)$ Calculated as the distance from the towing eye.

The height of the platform was $1200 \mathrm{~mm}$, the floor was $4.5 \mathrm{~m}$ long and $2.2 \mathrm{~m}$ width. The tracks and the wheel sizes were equal for both the trailers.

During the tests the hooking height of the two-axle trailer in tandem was $0.55 \mathrm{~m}$, while it was at $1.10 \mathrm{~m}$ for the two-axle trailer with turntable steering (Table 2).

\subsection{The Trailer's Load}

Cylinder coded logs of $1.5 \mathrm{~m}$ length (with a diameter ranging between 150 and $250 \mathrm{~mm}$ ) were piled on the trailers, transversely positioned in the forward direction. All the tests were performed with the same coded logs, positioned in the same former places on the trailer, to guarantee the same load distribution and to avoid different balances of the convoys. In addition, the tests were carried out both with the logs freely movable on the load floor (held by supports of steel fixed to the front and rear extremities of the floor) and with the logs tied (using two ropes, diagonally placed to the longitudinal axis of the trailer).

The gross mass (trailer and logs) did never exceed fifty percent of the tractor mass (about $6300 \mathrm{~kg}$ ), to ensure a safe convoy movement in very sloped conditions.

\subsection{The Crossed Path}

A $21 \mathrm{~m}$ sloped country dirt road with a flat area at its base was chosen to perform the trailer rollovers. The flat area was used to right the trailers after overturning and to collect the spread wood on the ground after the rollover. The crossed trail was transversal to the hillside and the path was $18 \%$ transversally and $32 \%$ longitudinally sloped.

An artificial wooden wedge (320 mm length, $110 \mathrm{~mm}$ height, and $220 \mathrm{~mm}$ width) was used as an obstacle to cause the trailer rollover. The obstacle was positioned in a place where the tractor was already in the flat area, to guarantee the safety of the tractor driver when the trailer overturned.

The trailer rollover, in fact, was determined by the impact of the front wheels of the trailer when it alighted along the path. 
In Figure 2 there is a sketch of an additional safety measure to avoid possible unpredictable accidents to the driver during the trailer rollover. For this purpose, an operator held the extremity of a rope twisted to the base of a stump and anchored at the other extremity to the top of the tractor's rollover protection structure (ROP) with a node.

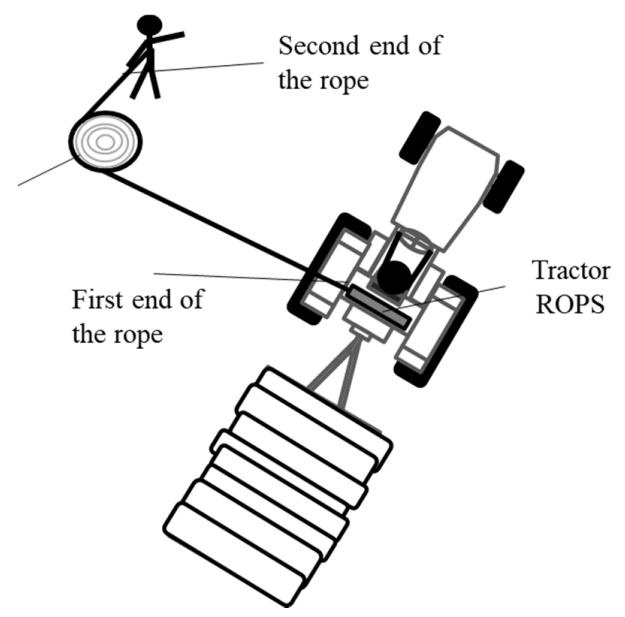

Figure 2. The used safety anchorage.

The rope was free to slide around the stump while the tractor moved forward. In the case of the risk of the tractor overturning, the operator could stop the rope sliding, thereby preventing the possible overturning of the tractor.

The average forward speed was about $3.2 \mathrm{~km} \mathrm{~h}^{-1}$. For each type of tractor, trailer, and load configuration (untied and tied logs), three overturning repetitions were carried out, with a total of 24 field tests.

\subsection{Measures}

Three types of measurement were carried out during the field tests:

- $\quad$ the detachment from the ground of the rear upstream wheels (or crawler)

- the transversal and longitudinal strains occurring when the trailer overturned (and released the hooking system of the tractor)

- $\quad$ the side-slipping (lateral deviation) of the rear wheels (or crawler) of the tractor

\subsection{Instruments}

A measurement tool, built ad hoc, was used to measure the height of the detachment of the wheels (or crawler) from the ground. The tool was a graduated plastic strip (scale: $1 \mathrm{~mm}$ ), rolled onto a reel without a return spring. A steel support (mass: $1 \mathrm{~kg}$ ) was used to connect the strip and was free to run on the ground by using a small rope linked to another support fixed to the tractor frame. The strip was maintained fully stretched before starting the test until the overturning of the trailer. When the wheels (or crawler) started to detach from the ground, the strip began to extend and the length difference before and after the overturning was a measure of the detachment height (Figure 3).

A mechanical tool was used to measure transversal and longitudinal strains. It was composed of a mechanical pendulum (length: $100 \mathrm{~mm}$ ) linked to a goniometer (diameter: $120 \mathrm{~mm}$ ) by a center hinge, where two metallic pointers were positioned and free to move (Figure 4). The zero point referred to the static position before starting the test, when the pointers were aligned to the pendulum. At the unrestrained extremity of the pendulum was fixed a mass of $20 \mathrm{~g}$. 


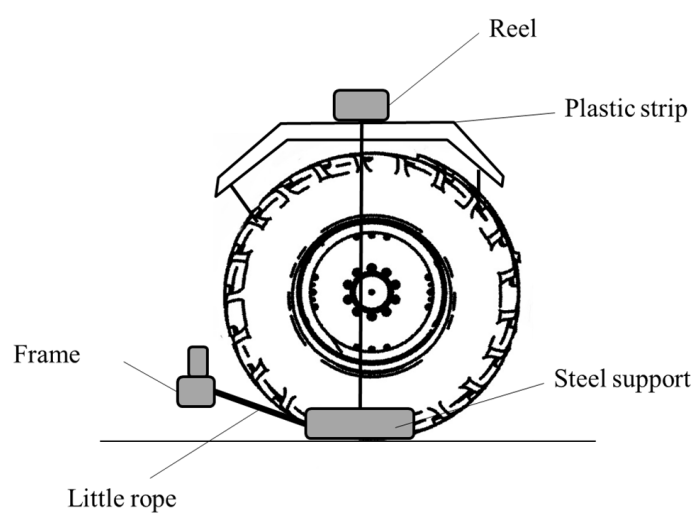

Figure 3. Scheme of the tool used to measure the detachment height of the wheel/crawler from the ground during the overturning of the trailer.

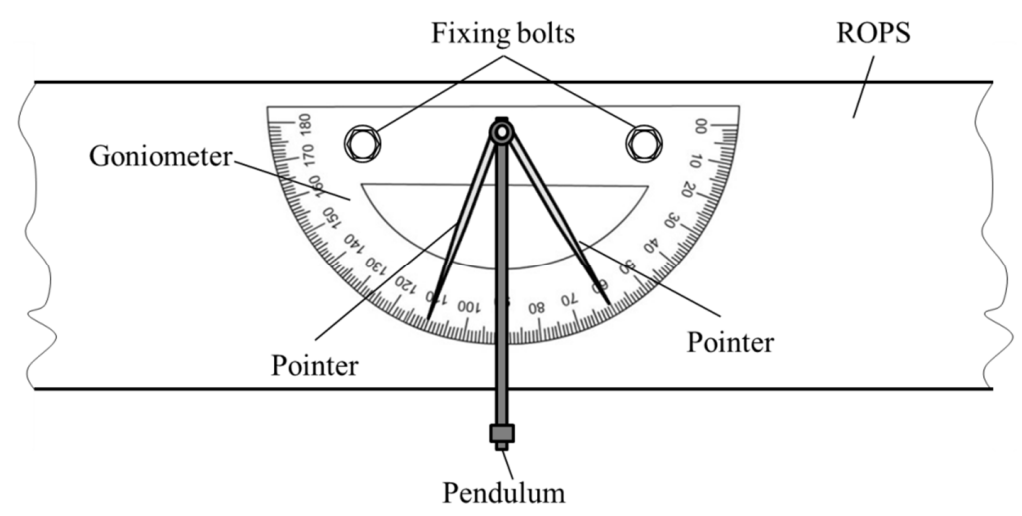

Figure 4. The tool used to measure the transversal and longitudinal strains.

Two mechanical tools were used, fixed by two bolts to the middle of the top of the ROP. The first pendulum was positioned orthogonally to the tractor's forward speed for measuring the transversal strains. To measure the longitudinal train the second pendulum was positioned parallel to the tractor's forward speed.

Positive measurements were clockwise. Transversal strains were positive at the left, negative at the right, while longitudinal measured strains were positive in the front, negative at the rear.

In the data elaboration only linear measurements were considered, because the goniometer measured the small displacements in linear units ( $\mathrm{mm}$ ).

A graduated steel ruler (precision: $1 \mathrm{~mm}$ ) was used to measure the side-slipping (lateral deviation) of the wheels (or crawler) of the tractors.

\subsection{Data Elaboration}

The elaboration of the data was performed using both Microsoft Excel and IBM SPSS V. 24.0 Statistic package [18]. In particular, the GLM (General Linear Model) was adopted in order to highlight differences between the considered treatments with a significance coefficient of 0.05 .

\section{Results}

\subsection{Lateral Deviation and Ground Detachment Height of the Tractor Wheels/Crawler}

In all the tests the lowest lateral deviation of the tractor wheels was produced by the two-axle trailer with turntable steering. The lateral deviations were limited to several centimeters and they were observed always on the rear axle of the tractor (Table 3). 
Table 3. Lateral deviation and ground detachment of the rear wheels (crawler) of the tractor in the different test configurations.

\begin{tabular}{|c|c|c|c|c|c|c|c|c|c|c|}
\hline \multirow{2}{*}{ Tractor } & \multirow{2}{*}{ Trailer } & \multirow{2}{*}{ Load } & \multicolumn{4}{|c|}{ Lateral Deviation $(\mathrm{cm})$} & \multicolumn{4}{|c|}{ Ground Detachment (cm) } \\
\hline & & & Mean & SD & Min & Max & Mean & SD & Min & Max \\
\hline \multirow{2}{*}{ Wheel } & Tandem & \multirow{4}{*}{ loose } & 3.5 & 0.6 & 2.8 & 3.9 & 3.6 & 0.7 & 2.8 & 4.1 \\
\hline & $\begin{array}{l}\text { Turntable } \\
\text { steering }\end{array}$ & & 2.2 & 0.4 & 1.8 & 2.6 & 0.0 & 0.0 & 0.0 & 0.0 \\
\hline \multirow{2}{*}{ Crawl } & Tandem & & 1.7 & 0.2 & 1.6 & 1.9 & 1.7 & 0.2 & 1.6 & 1.9 \\
\hline & $\begin{array}{l}\text { Turntable } \\
\text { steering }\end{array}$ & & 1.1 & 0.2 & 0.9 & 1.2 & 0.0 & 0.0 & 0.0 & 0.0 \\
\hline \multirow{2}{*}{ Wheel } & Tandem & \multirow{4}{*}{ tied } & 6.4 & 0.6 & 5.7 & 6.8 & 4.8 & 0.3 & 4.6 & 5.1 \\
\hline & $\begin{array}{l}\text { Turntable } \\
\text { steering }\end{array}$ & & 4.0 & 0.3 & 3.8 & 4.3 & 0.0 & 0.0 & 0.0 & 0.0 \\
\hline \multirow{2}{*}{ Crawl } & Tandem & & 3.8 & 0.2 & 3.6 & 3.9 & 3.5 & 0.7 & 2.9 & 4.2 \\
\hline & $\begin{array}{l}\text { Turntable } \\
\text { steering }\end{array}$ & & 2.7 & 0.2 & 2.5 & 2.9 & 0.0 & 0.0 & 0.0 & 0.0 \\
\hline
\end{tabular}

Lateral deviations ranged between 1.1 and $6.4 \mathrm{~cm}$ : the trailer with turntable steering highlighted the lowest lateral deviations in the crawled tractor, whereas the two-axle in tandem trailer showed the highest lateral deviation values when it was coupled with the wheeled tractor. The lateral deviation data doubled in the presence of the tied load, independent of the type of trailers.

The trailer with turntable steering did not cause rear wheel (or crawlers) detachment of the tractor from the ground, independent of the load type (tied or loose). On the contrary, the two-axle in tandem trailer gave a value of $3.6 \mathrm{~cm}$ with the wheel tractor and $1.7 \mathrm{~cm}$ with the crawler tractor when they were travelling with the loose load. These values increased up to two times in the presence of the tied load in the crawler tractor (Table 3).

\subsection{Longitudinal Strain}

Also measuring longitudinal strains, the highest values were found using the two-axle in tandem trailer when the load was tied. In detail, the maximum total longitudinal strain $(45 \mathrm{~mm})$ was recorded when the two-axle in tandem trailer was coupled with the wheeled tractor and the tied load. The minimum total longitudinal strain $(14 \mathrm{~mm})$ was observed using the two-axle with turntable steering trailer coupled to the crawled tractor and with the loose load. The highest longitudinal strains were observed with the tied load, independent of the trailer type. The crawler tractor better absorbed the strains caused by the trailer overturning (Table 4).

Table 4. Descriptive statistics of the longitudinal strains measured at the right and at the left sides of the wheel (crawler) of the tractor.

\begin{tabular}{|c|c|c|c|c|c|c|c|c|c|c|c|}
\hline \multirow{2}{*}{ Tractor } & \multirow{2}{*}{ Trailer } & \multirow{2}{*}{ Load } & \multicolumn{4}{|c|}{ Long. Strain Right (mm) } & \multicolumn{4}{|c|}{ Long. Strain Left (mm) } & \multirow{2}{*}{ Tota } \\
\hline & & & Mean & SD & Min & Max & Mean & SD & Min & Max & \\
\hline \multirow{2}{*}{ Wheel } & Tandem & \multirow{4}{*}{ loose } & 14.3 & 2.1 & 12.0 & 16.0 & -8.0 & 1.0 & -9.0 & -7.0 & 25.0 \\
\hline & $\begin{array}{l}\text { Turntable } \\
\text { steering }\end{array}$ & & 6.0 & 2.6 & 3.0 & 8.0 & -8.3 & 0.6 & -9.0 & -8.0 & 17.0 \\
\hline \multirow{2}{*}{ Crawl } & Tandem & & 9.0 & 1.0 & 8.0 & 10.0 & -8.3 & 0.6 & -9.0 & -8.0 & 19.0 \\
\hline & $\begin{array}{l}\text { Turntable } \\
\text { steering }\end{array}$ & & 7.0 & 1.0 & 6.0 & 8.0 & -5.3 & 1.2 & -6.0 & -4.0 & 14.0 \\
\hline \multirow{2}{*}{ Wheel } & Tandem & \multirow{4}{*}{ tied } & 19.0 & 1.0 & 18.0 & 20.0 & -21.7 & 3.1 & -25.0 & -19.0 & 45.0 \\
\hline & $\begin{array}{l}\text { Turntable } \\
\text { steering }\end{array}$ & & 14.3 & 1.5 & 13.0 & 16.0 & -15.0 & 3.0 & -18.0 & -12.0 & 34.0 \\
\hline \multirow{2}{*}{ Crawl } & Tandem & & 16.3 & 1.5 & 15.0 & 18.0 & -15.3 & 2.1 & -17.0 & -13.0 & 35.0 \\
\hline & $\begin{array}{l}\text { Turntable } \\
\text { steering }\end{array}$ & & 12.0 & 1.0 & 11.0 & 13.0 & -11.0 & 1.0 & -12.0 & -10.0 & 25.0 \\
\hline
\end{tabular}




\subsection{Transversal Strain}

In general, transversal strains were higher than longitudinal ones (Table 5) and the two-axle in tandem trailer caused the highest boosts on the tractor. The trailer with turntable steering generated transversal strains, always about 30\% lower than the two-axle in tandem trailer. Also in this case, the highest values (between 28 and $48 \mathrm{~mm}$ ) were observed with the tied load.

Table 5. Descriptive statistics of the transversal strains measured at the right and at the left sides of the wheel (crawler) of the tractor.

\begin{tabular}{|c|c|c|c|c|c|c|c|c|c|c|c|}
\hline \multirow{2}{*}{ Tractor } & \multirow{2}{*}{ Trailer } & \multirow{2}{*}{ Load } & \multicolumn{4}{|c|}{ Trans. Strain Right (mm) } & \multicolumn{4}{|c|}{ Trans. Strain Left (mm) } & \multirow{2}{*}{ Total } \\
\hline & & & Mean & SD & Min & $\operatorname{Max}$ & Mean & SD & Min & Max & \\
\hline \multirow{2}{*}{ Wheel } & Tandem & \multirow{4}{*}{ loose } & 14.7 & 1.5 & 13.0 & 16.0 & -17.3 & 2.1 & -19.0 & -15.0 & 31.0 \\
\hline & $\begin{array}{l}\text { Turntable } \\
\text { steering }\end{array}$ & & 8.0 & 1.0 & 7.0 & 9.0 & -6.0 & 1.0 & -7.0 & -5.0 & 14.0 \\
\hline \multirow{2}{*}{ Crawl } & Tandem & & 15.0 & 1.0 & 14.0 & 16.0 & -13.7 & 2.1 & -16.0 & -12.0 & 28.0 \\
\hline & $\begin{array}{l}\text { Turntable } \\
\text { steering }\end{array}$ & & 8.0 & 1.0 & 7.0 & 9.0 & -8.0 & 1.0 & -9.0 & -7.0 & 16.0 \\
\hline \multirow{2}{*}{ Wheel } & Tandem & \multirow{4}{*}{ tied } & 18.3 & 2.5 & 16.0 & 21.0 & -28.0 & 1.0 & -29.0 & -27.0 & 48.0 \\
\hline & $\begin{array}{l}\text { Turntable } \\
\text { steering }\end{array}$ & & 16.3 & 1.5 & 15.0 & 18.0 & -16.7 & 2.1 & -19.0 & -15.0 & 33.0 \\
\hline \multirow{2}{*}{ Crawl } & Tandem & & 17.0 & 2.0 & 15.0 & 19.0 & -20.0 & 2.0 & -22.0 & -18.0 & 37.0 \\
\hline & $\begin{array}{l}\text { Turntable } \\
\text { steering }\end{array}$ & & 14.0 & 1.7 & 12.0 & 15.0 & -14.3 & 1.5 & -16.0 & -13.0 & 28.0 \\
\hline
\end{tabular}

\subsection{Influence of the Tractor and Trailer Structure on Measured Parameters}

Data processing highlighted that the tractor and the trailer structure play an important role in the safety of the operator during trailer overturning. Concerning the lateral deviations, similarities were revealed by the General Linear Model (GLM) procedure with the same type of tractor and load system (Table 6).

Using the same statistical procedure, instead, all the parameters (tractor, trailer, and load type) produced different results for the measured ground rear wheel/crawler detachment (Table 7).

On the other hand, longitudinal strains were statistically similar with the tractor-trailer, trailer-load, and tractor-load combinations of parameters (Table 8). On the contrary, transversal strains were different considering all the combination of the parameters (Table 9).

Table 6. Statistical analysis (General Linear Model (GLM)) of the lateral deviation.

\begin{tabular}{cccccc}
\hline & SS & DF & SM & F Value & $p$ Value \\
\hline intercept & 239.402 & 1 & 239.402 & 1859.430 & $<0.0001$ \\
tractor & 17.340 & 1 & 17.340 & 134.680 & $<0.0001$ \\
trailer & 10.935 & 1 & 10.935 & 84.932 & $<0.0001$ \\
load & 26.042 & 1 & 26.042 & 202.265 & $<0.0001$ \\
tractor * trailer & 1.307 & 1 & 1.307 & 10.149 & 0.006 \\
tractor * load & 0.427 & 1 & 0.427 & 3.314 & 0.087 \\
trailer * load & 0.882 & 1 & 0.882 & 6.848 & 0.019 \\
tractor * trailer *load & 0.167 & 1 & 0.167 & 1.294 & 0.272 \\
\hline
\end{tabular}

Notes: $S S=$ Sum of Squares; DF = Default Freedom; MS = Squared Mean. 
Table 7. Statistical analysis (GLM) of the ground detachment.

\begin{tabular}{cccccc}
\hline & SS & DF & SM & F Value & $p$ Value \\
\hline intercept & 69.700 & 1 & 69.700 & 550.266 & $<0.0001$ \\
tractor & 3.920 & 1 & 3.920 & 30.951 & $<0.0001$ \\
trailer & 69.700 & 1 & 69.700 & 550.266 & $<0.0001$ \\
load & 3.450 & 1 & 3.450 & 27.240 & $<0.0001$ \\
tractor * trailer & 3.920 & 1 & 3.920 & 30.951 & $<0.0001$ \\
tractor *load & 0.120 & 1 & 0.120 & 0.951 & 0.344 \\
trailer *load & 3.450 & 1 & 3.450 & 27.240 & $<0.0001$ \\
tractor * trailer *load & 0.120 & 1 & 0.120 & 0.951 & 0.344 \\
\hline
\end{tabular}

Notes: SS = Sum of Squares; DF = Default Freedom; MS = Squared Mean.

Table 8. Statistical analysis (GLM) of the longitudinal strain.

\begin{tabular}{cccccc}
\hline & SS & DF & SM & $F$ Value & $p$ Value \\
\hline intercept & $13,680.375$ & 1 & $13,680.375$ & 1977.886 & $<0.0001$ \\
tractor & 187.042 & 1 & 187.042 & 27.042 & $<0.0001$ \\
trailer & 408.375 & 1 & 408.375 & 59.042 & $<0.0001$ \\
load & 1276.042 & 1 & 1276.042 & 184.488 & $<0.0001$ \\
tractor * trailer & 12.042 & 1 & 12.042 & 1.741 & 0.206 \\
tractor *load & 26.042 & 1 & 26.042 & 3.765 & 0.070 \\
trailer *load & 18.375 & 1 & 18.375 & 2.657 & 0.123 \\
tractor * trailer *load & 0.042 & 1 & 0.042 & 0.006 & 0.939 \\
\hline
\end{tabular}

Notes: SS = Sum of Squares; DF = Default Freedom; MS = Squared Mean.

Table 9. Statistical analysis (GLM) of the transversal strain.

\begin{tabular}{cccccc}
\hline & SS & DF & SM & $F$ Value & $p$ Value \\
\hline intercept & $20,768.167$ & 1 & $20,768.167$ & 3134.818 & $<0.0001$ \\
tractor & 88.167 & 1 & 88.167 & 13.308 & 0.002 \\
trailer & 1040.167 & 1 & 1040.167 & 157.006 & $<0.0001$ \\
load & 1093.500 & 1 & 1093.500 & 165.057 & $<0.0001$ \\
tractor * trailer & 37.500 & 1 & 37.500 & 5.660 & 0.030 \\
tractor *load & 60.167 & 1 & 60.167 & 9.082 & 0.008 \\
trailer *load & 28.167 & 1 & 28.167 & 4.252 & 0.036 \\
tractor * trailer *load & 0.167 & 1 & 0.167 & 0.025 & 0.876 \\
\hline
\end{tabular}

Notes: SS = Sum of Squares; DF = Default Freedom; MS = Squared Mean.

\section{Discussion}

The study showed that the trailer with a fixed drawbar (two-axle in tandem) caused higher strains (longitudinal and transversal) to the tractor during overturning of the trailer, compared to the trailer equipped with an "articulate" drawbar (presence of a turntable steering). In addition, adopting a trailer with turntable steering also permits the reduction of the risk of the tractor overturning, because in the event of the trailer overturning this type of trailer does not cause wheel or crawl detachment from the ground.

Nevertheless, these results are in contrast to what usually occurs in forestry yards, where trailers with fixed drawbars are preferred to trailers with an articulate drawbar [13,17]. In fact, the use of the first type of trailer guarantees a higher traction force because part of the load of the trailer weighs on the tractor; moreover, this type of trailer shows greater simplicity in field maneuvers due to the lower articulation points of the convoy structure.

The best performance of the trailer with turntable steering could be attributable to the higher number of junction joints (four swivel joints) in comparison to the trailers with fixed drawbar (two swivel joints) (Figure 5). In fact, the higher number of joint points guarantees greater quote compensation of the critical points during the trailer overturning (support points, coupling point, etc.) 
(Figure 6a). In contrast, a drawbar fixed to the trailer frame can cause higher instability of the tractor due to the overturning force on the coupling point of the tractor during trailer overturning (Figure 6b).

\section{Articulate drawbar}

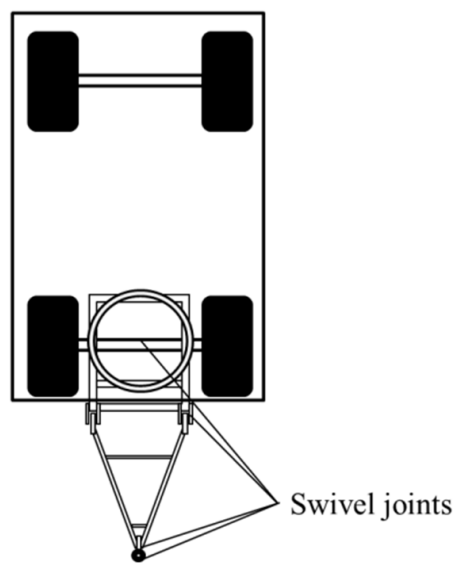

Fixed drawbar

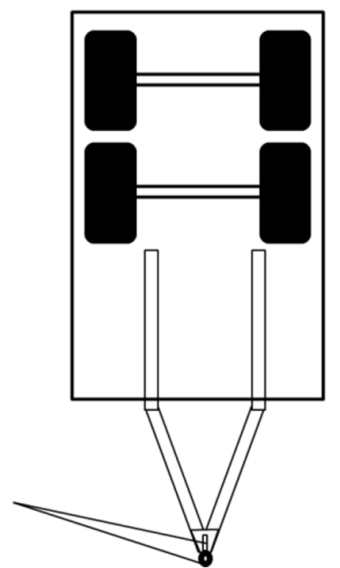

Figure 5. Swivel joints in the different drawbar types.
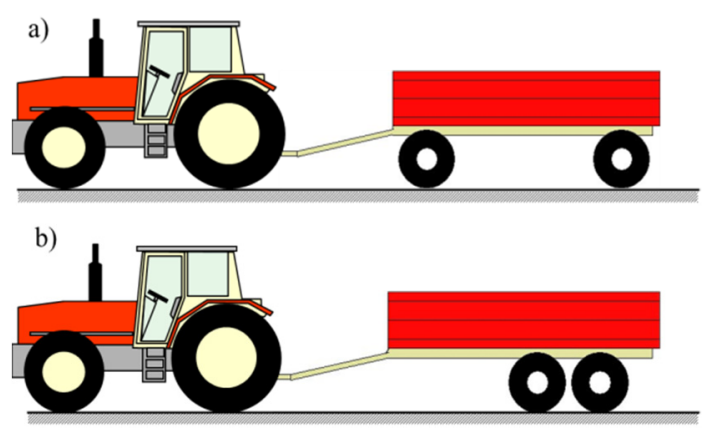
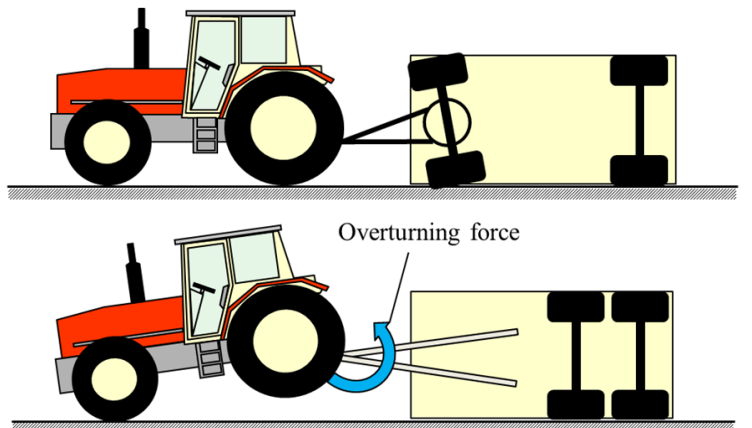

Figure 6. Scheme of the trailer overturning in flat soil in different configurations (two-axle trailer with turntable steering (a) and two-axle tandem trailer (b)).

Furthermore, the study highlighted that the loose load guaranteed better operator safety during trailer overturning; conversely, the tied load is dangerous because during trailer overturning its mass is added to the trailer mass and causes higher strains on the tractor.

Concerning the tractor propulsion system, the crawls guaranteed a better absorption of the strains caused by the trailer overturning: in fact, the crawler tractor, having a higher contact surface with the ground, had a better performance than the wheel tractor.

On the basis of these considerations, it is desirable that future studies on log transportation should also be focused on trailers with turntable steering. With this regard, tests were carried out on a double steering trailer prototype composed of two single-axle trailers [19]. This solution is very suitable for the transport of logs of high length (more than 8-10 m long) on narrow and steep forest roads to reduce the curve radius and to improve the convoy maneuverability. Nevertheless, considering the results obtained in this experiment, this prototype may produce the same strains for the trailer with a fixed drawbar during trailer overturning, because the first module of the prototype has a fixed single-axle drawbar.

\section{Conclusions}

In the Italian alpine territory two-axle tandem trailers are usually used for their technical characteristics (ease of maneuverability and high traction force due to the effect of part of their 
mass on the tractor), this study highlighted that the two-axle trailer with turntable steering is safer for the tractor driver during passages along transversal sloped terrains, where the risk of trailer overturning is high. This result is enhanced if a crawler tractor is used instead a wheeled one.

In addition, considering the effects due to the overturning of trailers tested in this study, it was found that, independent of the trailer type, a tied load is more dangerous than a load where the logs are freely movable on the load floor. In the first case, in fact, the logs form a single unit with the trailer mass which increases the transversal and longitudinal strains during the trailer overturning. The authors suggest that this study might be considered a valuable contribution if adopted for improving operators' safety in forestry yards.

Acknowledgments: We want to thank all the Italian forestry farmers that were available to conduct the field tests. Author Contributions: The authors equally contributed to all experimental design, elaboration, and paper editing. Conflicts of Interest: The authors declare no conflicts of interest.

\section{References}

1. Eurostat. Agriculture, Forestry and Fishery Statistics; Statistical Books; Publications Office of the European Union: Luxembourg, 2015.

2. Pessina, D.; Facchinetti, D. A survey on fatal accidents for overturning of agricultural tractors in Italy. Chem. Eng. Trans. 2017, 58, 79-84.

3. Cole, H.P.; Myers, M.L.; Westneat, S.C. Frequency and severity of injuries to operators during overturns of farm tractors. J. Agric. Saf. Health 2006, 12, 127-138. [CrossRef] [PubMed]

4. Myers, M.L.; Cole, H.P.; Westneat, S.C. Injury severity related to overturn characteristics of tractors. J. Saf. Res. 2009, 40, 165-170. [CrossRef] [PubMed]

5. Bernik, R.; Jerončič, R. The Research of the Number of Accidents with the Agriculture and Forestry Tractors in the Europe and the Main Reasons for those Accidents. Stroj. Vestn. J. Mech. Eng. 2008, 54, 557-564.

6. Blombäck, P.; Poschen, P.; Lövgren, M. Employment Trends and Prospects in the European Forest Sector; Geneva Timber and Forest Discussion Papers; United Nations: Geneva, Switzerland, 2003.

7. Spencer, H.B.; Gilfillan, G. An approach to the assessment of tractor stability on rough sloping ground. J. Agric. Eng. Res. 1976, 21, 169-176. [CrossRef]

8. Yisa, M.G.; Terao, H.; Noguchi, N.; Kubota, M. Stability criteria for tractor-implement operation on slopes. J. Terramech. 1998, 35, 1-19. [CrossRef]

9. Hunter, A.G.M. Stability of agricultural machinery on slopes. In Progress in Agricultural Physics and Engineering; Matthews, J., Ed.; CAB International: Wallingford, UK, 1991.

10. Chou, T.; Chu, T.W. An improvement in rollover detection of articulated vehicles using the grey system theory. Veh. Syst. Dyn. 2014, 52, 679-703. [CrossRef]

11. Melemez, K.; Di Gironimo, G.; Esposito, G.; Lanzotti, A. Concept design in virtual reality of a forestry trailer using a QFD-TRIZ based approach. Turk. J. Agric. For. 2013, 37, 789-801. [CrossRef]

12. Manzone, M.; Balsari, P. Electronic control of the motor axles of the forestry trailers. Croat. J. For. Eng. 2015, 36, 131-136.

13. Manzone, M. Performance of an electronic control system for hydraulically driven forestry tandem trailers. Biosyst. Eng. 2015, 130, 106-110. [CrossRef]

14. Bietresato, M.; Carabin, G.; Vidoni, R.; Mazzetto, F.; Gasparetto, A. A Parametric Approach for Evaluating the Stability of Agricultural Tractors Using Implements during Side-Slope Activities. Contemp. Eng. Sci. 2015, 8, 1289-1309. [CrossRef]

15. Pereira, D.; Fiedler, N.C.; de Souza Lima, J.S.; De Oliveira Bauer, M.; Rezende, A.V.; Missiaggia, A.A.; Pavesi Simão, J.B. Lateral stability limits of farm tractors for forest plantations in steep areas. Sci. For. 2011, 39, 433-439.

16. Lindroos, O.; Wasterlund, I. Theoretical potentials of forwarder trailers with and without axle load restrictions. Croat. J. For. Eng. 2014, 35, 211-219.

17. Spinelli, R.; Magagnotti, N.; Facchinetti, D. A survey of logging enterprises in the Italian Alps: Firm size and type, annual production, total workforce and machine fleet. Int. J. For. Eng. 2013, 24, 109-120. 
18. Keppel, G.; Wickens, T.D. Design and Analysis: A Researchers Handbook, 4th ed.; Pearson: Upper Saddle River, NJ, USA, 2004.

19. Marinello, F.; Grigolato, S.; Sartori, L.; Cavalli, R. Analysis of a double steering forest trailer for long wood transportation. J. Agric. Eng. 2013, 44, 10-15. [CrossRef] 